\title{
Reflexões psicanalíticas sobre a Resistência à Mudança organizacional
}

\author{
Psychoanalytic Reflections about Resistance to Organizational Change \\ Reflexiones Psicoanalíticas sobre la Resistencia al Cambio Organizacional
}

\author{
» Giovanna GARRIDO ${ }^{1}$ (Universidade Federal de São Carlos) \\ » Patrícia SALTORATO² (Universidade Federal de São Carlos) \\ » Carlos Augusto Amaral MOREIRA ${ }^{3}$ (Faculdade de Tecnologia de Americana)
}

ResumO Este artigo visa discutir a resistência à mudança enquanto fenômeno não racional. Objetivando refletir sobre o tema por um enfoque diferenciado, buscou-se analisar de que forma o inconsciente humano faz os gestores adotarem posturas reativas à mudança organizacional mesmo ela sendo imprescindível à sobrevivência das organizações. Sustentando-se em pesquisas bibliográficas de cunho psicanalítico e sociológico, este artigo estabelece uma hipótese central de que é possível considerar o comportamento resistente dos gestores como reflexo externo de lutas internas que ocorrem nestes indivíduos. As pesquisas realizadas mostraram indícios favoráveis a essa hipótese. Grande parte do comportamento dos gestores é resultante de angústias interiorizadas e reprimidas, que vão desde o medo da aniquilação até os modos de pensar que simbolizam o seu núcleo identitário. Os resultados apontam para a superficialidade das abordagens predominantes acerca do tema e promovem a abertura de caminhos para novos estudos que poderão ser realizados.

Palavras-Chave:

Gestor; comportamento; resistência; psicanálise.

\begin{abstract}
This study aims to discuss resistance to change as a non-rational phenomenon. Aiming to consider the theme through a different focus, the study sought to analyze how the human unconscious makes managers adopt reactive behaviors to organizational change even though it is indispensable for organizational survival. Based on bibliographic research, both psychoanalytic and sociological, this study is based on a central hypothesis that the resistant behavior of managers can be considered as external reflections of internal conflicts occurring in these individuals. The studies carried out presented favorable arguments for this hypothesis. In large part, the managers' behavior resulted from internalized and repressed anxieties, ranging between a fear of obsolescence and ways of thinking that symbolize their core identity. The results point to the superficiality of the predominant approaches to the theme and encourage opening paths to new research studies that might be undertaken. Keywords:

Manager; behavior; resistance; psychoanalysis.
\end{abstract}

1 Endereço para contato - Giovanna Garrido: Rua das Begônias, 698 - Parque Novo Mundo - Americana - SP - CEP: 13467-203. Fone: (19) 34612247 - (19) 996886753. E-mail: giovannagarrid@gmail.com.

2 Endereço para contato - Patrícia Saltorato: Travessa sete A, 52 - Jundiaquara - Araiçoaba da Serra - SP - CEP: 18190-000. Fone: (15) 997655700. E-mail: patrisal@dep.ufscar.br

3 Endereço para contato - Carlos Augosto Amaral Moreira: Rua Jenoefa Scaranello Magnusson, 64 - Residencial Vevey - Swiss Park - Campinas - SP - CEP: 13049-475. Fone: (19) 34065776, Ramal 222. E-mail: guana@uol.com.br. 
Este artículo pretende discutir la resistencia al cambio en tanto un fenómeno no racional. Con el objetivo de reflexionar sobre el tema desde un enfoque diferenciado, se trató de analizar de qué manera el inconsciente humano hace que los gestores adopten posiciones reaccionarias al cambio organizacional aunque este sea imprescindible para la supervivencia de las organizaciones. Basándose en una investigación bibliográfica de orientación psicoanalítica y sociológica, el presente artículo parte de la hipótesis de que es posible considerar el comportamiento resistente de los gestores como reflejo externo de luchas internas que ocurren en estos individuos. Las investigaciones realizadas mostraron evidencias en favor de esta hipótesis. Gran parte del comportamiento de los gestores es resultado de angustias interiorizadas y reprimidas, que van desde el temor de la aniquilación hasta formas de pensamiento que simbolizan su núcleo de identidad. Los resultados señalan la superficialidad de los enfoques predominantes acerca del tema y promueven la apertura de caminos hacia nuevos estudios que podrán ser realizados.

Palabras-clave:

Gestores; comportamiento; resistencia; psicoanálisis.

$\mathrm{M}$ uitas são as discussões na sociedade referentes à relação existente entre a necessidade da mudança e o comportamento resistente das pessoas. Porém, esses debates baseiam-se excessivamente na racionalidade e, na busca pela compreensão do tema, é dado maior valor aos pressupostos que o norteiam do que às reações emocionais que fazem os indivíduos adotarem tal comportamento.

Ao tratar desse tema, busca-se encontrar explicações por uma visão estreita, não considerando que a organização, composta por indivíduos, é um sistema complexo. Nessa visão, cujo foco analítico é o comportamento diretamente observável, os sujeitos são vistos como lógicos e racionais.

Além disso, a maioria das abordagens acerca da resistência está relacionada à figura do empregado da organização. Contudo, nota-se a relevância de outro enfoque, pois existem situações em que as empresas convivem com a necessidade da mudança, porém não a executam devido ao comportamento resistente de seus gestores.

De qualquer forma, as análises sobre o tema não dispensam muita importância ao interior do sujeito, repleto de expectativas, de medos e de ansiedades. Porém, é impossível compreender o comportamento dos indivíduos no contexto da mudança organizacional sem observar o processo por meio do qual eles interpretam e constroem significados para eventos nos quais estão envolvidos. Ou seja, a análise da personalidade do sujeito e de seus processos inconscientes é imprescindível para compreender o comportamento resistente.

Nesse contexto, fundamentado no estudo da resistência dos gestores à mudança e com auxílio de algumas abordagens psicanalíticas da metáfora das prisões psíquicas de Morgan (2007), este artigo reflete sobre o tema com o propósito de encorajar as pessoas a desafiar os paradigmas que sustentam essas discussões. Assim, o objetivo geral é analisar a maneira como forças inconscientes podem fazer os gestores adotarem comportamentos resistentes à mudança organizacional, mesmo ela sendo imprescindível para a sobrevivência. Como observado, a figura do gestor é o objeto de aporia deste estudo e todas as argumentações estruturadas visam estabelecer até que ponto é possível entender a resistência deles à mudança como reflexo externo de suas lutas internas.

A problemática do artigo parte da premissa de que a vida organizacional é constituída por muitas dimensões inconscientes. Dessa forma, diversos fenômenos possuem explicações de âmbito não racional. Em uma organização, forças psíquicas agem em dimensões ocultas no comportamento dos gestores e os fazem resistentes às mudanças que alteram sua maneira habitual de encarar a realidade. Portanto, para entendermos esse comportamento, é preciso entender primeiro o "outro" que existe dentro do gestor.

Desse modo, o artigo está estruturado da seguinte forma: primeiro, será demonstrada a forma como o estudo foi conduzido; depois, será apresentado o referencial teórico, subdividido em três tópicos principais. Primeiro, é feita uma discussão introdutória da mudança organizacional, buscando relacioná-la com a sobrevivência das organizações. Em seguida, são analisados os principais pontos da resistência à mudança, visando explicitar sua proximidade com a mudança organizacional e apresentar alguns argumentos críticos referentes aos pressupostos acerca do tema, de forma a direcionar o artigo à análise pretendida nesse momento. $\mathrm{O}$ terceiro tópico traz a discussão central, analisando o comportamento resistente dos gestores a partir da psicanálise. Nessa parte, é abordada a relação estabelecida entre o indivíduo e a organização e de que forma o seu significado oculto, junto ao inconsciente humano, pode suscitar comportamentos conservadores nos gestores. Por fim, apresentam-se as conclusões alcançadas no estudo. 


\section{MÉTODO}

O estudo foi realizado por meio de uma abordagem qualitativa, visando abordar o objeto da pesquisa sem a preocupação de medição ou quantificação dos dados obtidos.

Em relação à classificação do estudo, foi estabelecida como base a taxionomia de Vergara (2009). Quanto aos fins, a pesquisa foi exploratória e explicativa. Exploratória, pois, embora o tema em questão seja bastante antigo e já difundido na realidade empresarial, não se verificou a existência de muitos estudos que o abordem com o ponto de vista proposto neste artigo, restrito ao comportamento resistente dos gestores agentes de mudanças. Explicativa, pois visa esclarecer, por meio de abordagens psicanalíticas, os fatores que podem contribuir para a postura resistente desses indivíduos ao se depararem com a necessidade de promoverem mudanças. Quanto aos meios, o estudo foi bibliográfico, sustentado por referenciais teóricos acessíveis ao público em geral.

Assim, com o auxílio de algumas abordagens teóricas, foram investigados os méritos conceituais de alguns assuntos e a forma como se relacionam: mudança organizacional, resistência à mudança e alguns aspectos psicanalíticos condizentes ao tema, em especial aqueles relacionados à metáfora das prisões psíquicas.

\section{Mudança Organizacional}

Historicamente, identificam-se dois períodos no desenvolvimento dos estudos organizacionais que incidem diretamente no tema da mudança organizacional. Até 1950, os estudiosos se concentravam na figura do gerente, considerado agente único promotor de mudanças. Nessa época, as organizações eram concebidas como sistemas fechados, ou seja, subestimavam-se as influências do ambiente externo. Robbins, Judge e Sobral (2010) complementam que a mudança organizacional ocorria esporadicamente, sendo considerada um distúrbio ocasional em um mundo pacífico e previsível.

Entretanto, após 1950, com a teoria dos sistemas e da contingência, e diante da crescente incerteza ambiental, admitiu-se que o ambiente influenciava no funcionamento organizacional. Por volta de 1970, consolidou-se o reconhecimento de que existem situações aleatórias, advindas do ambiente externo, que fogem ao controle e à influência dos dirigentes (Dias, 2008).

Segundo Robbins et al. (2010), diante da mudança no cenário, a estabilidade e a previsibilidade caracterizadas na abordagem episódica tornaram-se obsoletas. Nesse novo contexto, o processo de adaptação organizacional deve ser sensitivo e dinâmico. A flexibilidade tornou-se desesperadamente necessária, consistindo em uma das molas da imortalidade empresarial (Freitas, 1999).

Neri (2005) afirma que essa realidade vem alimentando o assunto da mudança organizacional a cada dia, tornando-o um monstro mitológico que só pode ser combatido com as inovações geradas por ele. Diante disso, as questões ligadas à sobrevivência empresarial tornam-se assustadoramente reais, pois todo o sistema está sujeito à entropia, um processo de deterioração e destruição dele mesmo (Spector, 2002). Assim, para deter esse processo, manter a homeostase e sobreviver, a organização precisa importar energia do ambiente e estar apta a promover mudanças.

Portanto, a sensibilidade é imprescindível para as empresas. Segundo Thiry-Cherques (1995), o que acontece com as organizações é uma fiel imagem da seleção natural. O alcance do sucesso e da sobrevivência organizacional exige uma luta constante contra o passado e contra o obsoletismo de suas maneiras de pensar e agir (Motta, 1998).

Entretanto, Motta (1998) enfatiza que a promoção da mudança não dispensa as interpretações e as experiências individuais. Qualquer interpretação das representações ambientais é feita por meio da percepção individual do gestor. Agir a favor ou contra a mudança é uma questão de posicionamento pessoal.

Desse modo, pode-se dizer que a mudança não é promovida simplesmente por decreto das forças ambientais. Uma transformação organizacional é o reflexo dos desejos autênticos de seus gestores e da forma como encaram a realidade que os cerca. Assim, qualquer comportamento adotado por eles provém do âmbito pessoal. Afinal, todos os processos decisórios são orientados segundo o próprio bem-estar daqueles que gerem as organizações (Freitas, 1999).

\section{Resistência à Mudança}

Nota-se que as organizações travam uma luta sem tréguas para a sobrevivência. Todavia, é evidente a resistência que ainda persiste na aceitação de que elas se deparam com um ambiente selecionador que exige sensibilidade, dinamismo e adaptação e que a mudança não é só fundamental, mas imprescindível. 
Segundo Motta (1998), existem pessoas que ainda não se conscientizaram e olham as mudanças apenas como variações das práticas passadas, cujo impacto é pequeno. $\mathrm{O}$ autor ressalta que, temendo a perda dos ideais já estabelecidos, elas ignoram que a realidade exige das empresas uma direção em meio ao caos e à vulnerabilidade, um confronto com as ambiguidades. Ou seja, exige a adoção de comportamentos favoráveis à mudança como alternativa de sobrevivência. Ao invés disso, preferem continuar da forma que estão.

Dias (2008) explica essa dificuldade de ajustamento ressaltando que a desconfiança e a incerteza sempre se manifestam com a mudança, pois as pessoas se sentem ameaçadas em seu estado atual. Inseguras em relação à obtenção e à manutenção de seus interesses particulares, elas resistem às alterações propostas, mantendo a situação anterior à mudança. Motta (1998) explica tal resistência pelo fato de que a mudança, ao mesmo tempo em que promete, desestabiliza o meio, pois submete os indivíduos a novas interpretações da realidade.

É por isso que, em épocas de mudanças, forças desintegradoras tornam-se mais visíveis nas empresas, pois toda inovação mobiliza as pessoas e atinge suas razões, interesses e emoções (Motta, 1998). Assim, as organizações continuam dando preferência aos padrões tradicionais e buscam a eficiência resistindo ao que traz variabilidade ao meio, ou seja, adotam posturas inadequadas à instabilidade característica do contexto organizacional, pois resistem em reinventar a si próprias (Souza, 2002).

Em relação à resistência, testemunha-se uma densa literatura empenhada na busca pelas possíveis causas de tal comportamento (Thomas \& Hardy, 2011). Porém, grande parte dessa teoria está fundamentada em pressupostos que se portam como suposições tácitas sobre esse tipo de comportamento (Bringselius, 2010).

Hernandez e Caldas (2001) relatam que tais pressupostos foram pouco modelados ou testados, portanto, possuem baixa sustentação teórica, como, por exemplo, o predomínio da abordagem massificada das manifestações resistentes. Os autores explicam que em tal abordagem os indivíduos organizacionais são representados como um corpo homogêneo que demonstra a resistência como um agregado, o que desconsidera totalmente as diferenças individuais e a forma como cada pessoa enxerga a mudança.

Em relação a isso, Silva e Vergara (2003) argumentam que é fruto de um pensamento ingênuo a ideia de que é possível fazer uma coletividade de sujeitos pensantes interpretarem a realidade segundo uma ótica padronizada. Para os autores, "as manifestações de resistência são, antes de tudo, manifestações de emoções, de ansiedade, de angústia, de raiva e de nostalgia” (p.19), ou seja, reflexões das lutas interiores de cada indivíduo.

Outro ponto contraditório é o que pressupõe que os seres humanos são naturalmente resistentes à mudança, sendo esta uma característica inata ao indivíduo. Tal hipótese assume uma posição muito generalista. É certo que os indivíduos sempre reagem às ameaças que colocam em risco o equilíbrio preexistente e geram incertezas, porém, não agem assim simplesmente pela natureza.

São diversas as teorias que explicam o comportamento resistente. Morgan (2007) destaca as abordagens psicanalíticas, tendo em vista a ligação entre a organização, o inconsciente e o comportamento humano e o fato de que muito do que acontece nas organizações possui significados inconscientes. De qualquer maneira, nota-se que a resistência à mudança vai muito além de um fenômeno inato aos indivíduos.

Há outro pressuposto a ser discutido que diz respeito ao fato de que os empregados são os atores organizacionais com maior probabilidade de resistência. Porém, conforme afirma Lewin (1947), a resistência à mudança é um fenômeno sistêmico que ocorre tanto com empregados quanto com gerentes.

Motta (1998) corrobora dizendo que é possível examinar a resistência pela congruência ou incongruência das pessoas com a organização. $\mathrm{O}$ autor explica que um ser congruente é aquele que integra a organização a ponto de construir nela a sua identidade, ou seja, seus valores individuais são consonantes com os organizacionais. Assim, o autor defende que a maioria dos indivíduos congruentes constitui o grupo dirigente da organização e que se trata de pessoas pouco favoráveis à mudança, temerosas da perda de seus direitos e privilégios. Para o autor, a resistência desses indivíduos se prende ao status organizacional, buscando, continuamente, fortalecer, consentir e manter as mesmas regras do jogo.

Com um raciocínio semelhante, Fligstein e McAdam (2012) enfatizam que os indivíduos que respondem de forma mais conservadora às ameaças percebidas no ambiente são os que têm mais poder. Para os autores, tais indivíduos lutam tenazmente para preservar aquilo que se constitui como fonte política e cultural de suas próprias vantagens e interesses.

Assim, diante disso, torna-se visível a perspectiva estreita pela qual o tema é tratado e a fragilidade dos pressupostos assumidos por grande parte das teorias relacionadas, tendo em vista que as discussões acerca do tema baseiam-se excessivamente na racionalidade. É possível verificar também que, na busca pela compreensão 
de tal fenômeno, os pressupostos norteadores são mais valorizados do que as próprias reações emocionais que levam ao comportamento dos indivíduos. Ressalta-se que, para melhor entender os fenômenos organizacionais, deve-se observar o lado não visível da organização. Centrar-se somente nas formalidades organizacionais impede a percepção dos processos reais, afetivos e sociais que as afetam (Enriquez, 2000b).

Para Silva e Vergara (2003), o consenso adotado pelas teorias e práticas a respeito do tema não deixa de ser uma utopia assumida na tentativa de simplificar o que é, pela própria natureza, complexo: o comportamento humano.

\section{Resistência à Mudança à Luz de Abordagens Psicanalíticas}

Neste tópico, serão discutidos alguns conceitos ligados ao comportamento resistente dos indivíduos frente às mudanças e, mais especificamente, será analisada a resistência dos gestores do ponto de vista psicanalítico, visando esclarecer que grande parte das ações resistentes provém do âmbito não racional, isto é, são reflexos externos das lutas psíquicas destes indivíduos.

$\mathrm{Na}$ primeira parte será discutido o significado atribuído à organização pelos indivíduos. A segunda retrata a forma como o indivíduo constrói a realidade organizacional, vendo-a como seu próprio espaço pessoal digno de ser preservado. A dificuldade de aceitação das mudanças organizacionais é tratada na terceira parte, a partir da descrição da alegoria da caverna de Platão, sendo retomada na discussão mais profunda da problemática deste estudo na última parte.

Indivíduo frágil x organização protetora. Freitas (1999) afirma que o caráter acelerado e interdependente das mudanças faz a compreensão do momento se perder, e argumenta que as próprias mudanças, pela sensação de futuro incerto que remetem, também geram certa desorientação, dúvida e confusão no sujeito.

Segundo Freitas (1999), o indivíduo, considerado o elo mais frágil da cadeia social e suscetível aos impactos das diversas mudanças que ocorrem ao seu redor, passou a enfrentar uma crise de identidade - em relação às perturbações que ocorreram nos seus processos de identificação e ao enfraquecimento de suas fontes e imagens identificatórias. Conforme a autora, a ancoragem no universo simbólico do passado foi perdida, suas referências sociais e seus valores tradicionais, até então aceitos como norteadores da vida, foram quebrados, gerando uma perda de seu próprio núcleo identitário e coeso.

Para Freitas (1999), os efeitos que o indivíduo sofre durante tal crise, caracterizada como um processo de mudanças violentas, não são passíveis de análise objetiva e racional, mas se manifestam no comportamento, nas atitudes, assim como na esperança do futuro. Pelo fato de os vínculos sociais do passado revelarem-se caducos e enganosos, o indivíduo é dominado por um grande mal-estar.

Freitas (1999) argumenta que, à medida que o aspecto social deixa de garantir suporte e segurança para uma mínima compreensão do presente e certa esperança em relação ao futuro, o indivíduo tende a se agarrar mais a si próprio e àquilo que possa reduzir sua fragilidade para garantir um referencial menos instável diante do incerto e do desconhecido.

Assim, Pagès, Gaulejac, Bonetti e Descendre (1987) afirmam que o indivíduo criou uma imagem inconsciente bastante rígida da organização, já que a enxergou como uma formação psíquica capaz de fornecer respostas às suas próprias necessidades de segurança psicológica frente ao ambiente mutante que o cerca. Dessa forma, a organização e a estrutura psicológica do indivíduo tornaram-se peças de um sistema sociomental que se reforça mutuamente, ou seja, a organização é uma leitura do indivíduo e o indivíduo é uma leitura da organização, conforme complementam os autores.

Diante de tal crise de identidade, as empresas passam a se posicionar como detentoras de um grande poder. Freitas (1999) explicita que elas surgem como um novo ícone, um novo referencial, e prometem acompanhar o indivíduo em toda a solidão resultante dessas mudanças. Dessa forma, em decorrência da projeção do indivíduo, a organização se torna um objeto de identificação e de amor e uma fonte de prazer, alimentando e fixando sua angústia. Consequentemente, segundo Pagès et al. (1987), o indivíduo se torna dependente da organização, não apenas para sua existência material, mas também para a integridade de sua própria identidade.

Para Enriquez (2000b), apresentando-se como todo-poderosa, a organização torna-se fornecedora de todos os elementos de segurança capazes de saciar o desejo de completude do indivíduo, visto que, segundo o autor, o ser humano carrega consigo uma falha irremediável, uma angústia original relacionada à necessidade de ser protegido e nutrido por um ser fora do comum. Para Moreira (2005), esse sentimento de fragilidade e de finitude do sujeito é algo que marca seu nascimento e o acompanha até a morte. Até mesmo o amadurecimento e a 
vida adulta não escondem essa fragilidade. Assim como na infância, o indivíduo continua buscando algo para se identificar. Ele tem nostalgia dos pais, ou seja, da mãe-nutriz e do pai-protetor, complementa Freitas (1999).

O espaço do indivíduo na organização: uma realidade artificial. É assim que, diante desse significado oculto que delimita a relação de ambos, o indivíduo constrói, na organização, seu espaço pessoal. É na organização que o indivíduo projeta suas crenças, suas tradições, seus valores, seus medos, enfim, é nela que ele constrói sua própria realidade. Referindo-se à construção da realidade, Freitas (1999) relata que é esse conjunto de normas, valores e mitos produzidos na vivência organizacional do sujeito que assume o caráter de realidade e é ela que dita o comportamento e, ao mesmo tempo em que nutre, contamina pensamentos e atitudes. É por isso que Motta (1998) encara a realidade organizacional como uma interpretação ativa do indivíduo sobre si próprio, que deve ser entendida de uma forma fenomenológica e intersubjetiva.

Assim, ao projetar seu próprio espaço pessoal na organização, o sujeito a vê como uma aura que o envolve diretamente, uma zona emocional que o protege, cujas dimensões variam segundo fatores psicológicos e culturais. Dessa forma, esse espaço será sempre visto como um ponto de fixação e um local de enraizamento (Fischer, 2010), que o protege do despertar de seus conflitos neuróticos e psicóticos. Mergulhado nesse sistema de significados, o indivíduo tranquiliza sua própria subjetividade (Fligstein \& McAdam, 2012).

É por essa razão que Morgan (2007) explora o entendimento das organizações como prisões psíquicas. O autor afirma que elas são criadas e sustentadas por processos conscientes e inconscientes com a noção de que o indivíduo pode se tornar um verdadeiro prisioneiro das imagens, das ideias, dos pensamentos e das ações que estes processos originam e, consequentemente, acaba se prendendo a construções da realidade que lhe garantem uma visão imperfeita do mundo. Para o autor, os indivíduos têm uma inclinação por caírem nas armadilhas criadas por eles mesmos junto à organização. Os sujeitos se prendem em construções artificiais da realidade que, para eles, é tudo o que existe.

A dificuldade de aceitar as mudanças - alegoria da caverna de Platão. A alegoria da caverna de Platão é uma parábola que ilustra a reflexão sobre a realidade artificialmente construída pelo indivíduo na organização. Tal alegoria descreve alguns indivíduos que habitam o interior de uma caverna, cuja entrada é voltada à luz de uma fogueira crepitante. Esses sujeitos estão presos e posicionados de costas para a entrada da caverna e tudo o que são capazes de ver é a parede, iluminada pela claridade das chamas que nela projetam sombras de pessoas e objetos. Assim, esse "teatro de sombras" é a única coisa que as pessoas da caverna veem e, como estão ali desde que nasceram, tomam as sombras por realidade, atribuem-lhes nomes, conversam com elas e até mesmo fazem a ligação dos sons externos com os movimentos que observam na parede.

É assim que um dos indivíduos da caverna consegue se libertar da prisão. Primeiro, ele se pergunta de onde vêm aquelas sombras projetadas na parede; depois, começa a perceber que elas nada mais são do que reflexos obscuros de uma realidade mais complexa e vê que as percepções de seus antigos companheiros são imperfeitas e distorcidas.

Se o indivíduo voltasse à caverna, não seria capaz de viver como antes, visto que para ele o mundo seria um lugar diferente e teria dificuldade em aceitar o confinamento. Se tentasse compartilhar com seus colegas seu novo conhecimento, seria ridicularizado, já que as imagens com as quais acostumaram possuem um significado superior a um mundo nunca visto. Além disso, já que o indivíduo portador do novo conhecimento não seria capaz de agir com convicção em relação às sombras, seus próprios companheiros passariam a ver o mundo exterior como algo perigoso, a ser evitado. Tal experiência poderia, na verdade, fazê-los se apegarem ainda mais à sua maneira habitual de encarar a realidade. Mesmo assim, o indivíduo liberto decide voltar e tenta explicar aos outros que as sombras na parede não passam de imitações da realidade. Porém, os demais não concordam e continuam afirmando que aquilo que veem é tudo o que existe e, por fim, acabam matando-o (Gaarder, 1995; Morgan, 2007).

Por meio da análise dessa metáfora, é possível refletir sobre vários aspectos a respeito da resistência às mudanças. Pode-se dizer que ela constrói, de maneira simbólica, a imagem da organização, isto é, na realidade organizacional, a maioria das pessoas se apega aos reflexos das ideias no mundo dos sentidos, se satisfaz com sua vida em meio a esses reflexos e acredita que as sombras são tudo o que existe (Gaarder, 1995).

O comportamento resistente dos gestores. Ao ver a organização como seu espaço pessoal, o indivíduo se prende a ela como em um ambiente que se autoisola. Assim, tende a rodear seu espaço com muros e fronteiras e qualquer intrusão é vista como ameaça (Fischer, 2010). Isso porque, no ambiente empresarial, alguns arranjos organizacionais podem assumir especial significância e ser preservados e mantidos mesmo em face de grande 
pressão para a mudança, ou seja, desempenham um papel crítico na definição da natureza e da identidade das organizações e de seus membros. Pode-se dizer que as estruturas, os padrões culturais, as crenças e os comportamentos são fenômenos profundamente pessoais e não somente corporativos (Morgan, 2007).

Dessa forma, segundo relatos de Morgan (2007), qualquer tentativa de promover uma modificação desses fenômenos mobiliza oposições diversas porque, para o indivíduo, a busca pela defesa de seu status quo é uma tentativa de defesa de seu próprio "eu". Além disso, Fischer (2010) acrescenta que, quanto maior o nível de hierarquia do indivíduo, maior é a valorização desse espaço e mais estruturadas são as fronteiras e os muros de proteção às ameaças, pois as estruturas, as regras e os costumes enraizados podem ser considerados aspectos cruciais na criação de limites e de rigidez que simbolizam a percepção de quem o gestor realmente é (Fligstein \& McAdam, 2012; Morgan, 2007).

Souza (2002) afirma que é por esse motivo que o caminho até a mudança é um tanto doloroso e complexo, já que ideias inovadoras não se encaixam no modo particular de pensar. É um trajeto que exige questionar a ilusória segurança que o indivíduo encontra na organização. Assim, os gestores, presos em fortes laços de resistência, muitas vezes priorizam a estabilidade e continuam apegados rigidamente aos aspectos particulares de seus mundos.

Desse modo, diversos fatores podem ser analisados para compreender o motivo pelo qual esses indivíduos adotam comportamentos conservadores frente à necessidade de promoverem mudanças. Thiry-Cherques (1995) afirma que esse comportamento pode ser interpretado pelo menos de duas formas: culturalmente e psicologicamente.

No que se refere ao fator cultural, Grün (1999) afirma que é sempre importante dar atenção especial à lógica culturalista que circunscreve a abertura ou não de caminhos para a mudança organizacional. Os indivíduos são rodeados por visões de mundo e construções da realidade sustentadas por forças econômicas e simbólicas. Desse modo, a formulação de um ponto de vista ou de um modo de pensar sempre resulta de uma filtragem cognitiva da realidade e, consequentemente, se estabelece como algo difícil de ser descartado da personalidade, que acaba conduzindo o indivíduo a dispensar certa valoração negativa àquilo que se contrapõe à atual forma de pensar (Grün, 1999).

Assim, pode-se dizer que a visão conservadora dos gestores é a própria exteriorização daquilo que está enraizado na consciência deles, ou seja, a exteriorização de suas construções ideológicas. Tal colocação faz menção à sensibilidade cultural que permeia o comportamento resistente. Uma vez que a forma de pensar, os valores, as crenças e os ritos se tornam institucionalizados e enraizados, a realidade é filtrada e esses indivíduos se tornam capazes de enxergar somente aquilo que reitera suas formas de pensar, incorporando aquilo que reforça e rejeitando aquilo que ameaça e contradiz (Grün, 1999).

DiMaggio (1997) acrescenta que o cognitivo do indivíduo percebe mais facilmente aquilo que é consonante à sua estrutura de suposições padrões, garantidora de sua estabilidade individual. Ou seja, a própria estrutura mental do sujeito influencia na sua percepção e interpretação dos fatos e, assim, as formas comportamentais institucionalizadas são reproduzidas legitimamente.

Zucker (1977) afirma que a resistência à mudança é afetada pela institucionalização. A autora enfatiza que quanto mais elevado o grau de institucionalização, maior é a resistência à mudança, pois ela induz à estabilidade e à persistência em relação às formas e aos comportamentos estruturais (Fleck, 2007).

Ressalta-se a concepção supersocializada do gestor como sujeito, isto é, todos os ideais nos quais se socializou têm vida estável e, uma vez concretizados e institucionalizados, a reiteração se torna um fenômeno inerte e o caráter conservador é dificilmente descartado de sua personalidade (Grün, 1999).

Por outro lado, ao interpretar a resistência enfatizando o lado psicológico, pode-se dizer que o caráter conservador dos gestores é considerado uma resistência no âmbito pessoal. Embora sustentadas em modelos ultrapassados, as bases tradicionais de gestão são vistas como garantidoras de segurança. Assim, os gestores nem ousam em pensar em novos modelos, nem em implementar novas práticas de gestão. Nessa realidade, é mais fácil dizer não ao desconhecido do que descobrir o futuro e enxergar além dos limites dos paradigmas vigentes (Motta, 1998; Souza, 2002).

Segundo Motta (1998), diante da impossibilidade de conhecer o futuro, o indivíduo o enxerga de forma receosa, como um fantasma ameaçando o equilíbrio do presente. Ao invés de aceitá-lo e buscar descobri-lo, o sujeito opta por aquilo que já lhe é familiar, conhecido e experimentado. Ele se prende aos seus ideais e torna-se incapaz de correr riscos ou de contrapor-se aos hábitos previamente estabelecidos. 
Desta forma, assim como afirmam Silva e Vergara (2003), a tentativa de compreender esse comportamento humano no contexto das mudanças não pode ignorar fatores como a personalidade dos indivíduos. É certo que as dimensões subjetivas são um pouco esquecidas ao se tratar da relação entre o indivíduo e a organização (Lapierre, 2010). Porém, Morgan (2007) sugeriu que muito do que acontece em um nível superficial explica a estrutura oculta e dinâmica da psique do sujeito. Para o autor, não é possível livrar as organizações das forças reprimidas à espreita na sombra da racionalidade, elas se manifestam no comportamento humano. No parecer de Motta (1998), os indivíduos são prisioneiros de suas próprias mentes e as qualidades que lhes são inerentes influenciam cada ação realizada, ou seja, a forma como o pensamento é construído precede e domina a ação.

Em relação a esses pontos, Morgan (2007) constrói uma metáfora comparando as organizações com prisões psíquicas, reconhecendo que as pessoas podem se tornar prisioneiras de suas próprias maneiras de pensar e agir. Essa metáfora é construída por meio de algumas abordagens psicanalíticas acerca da resistência, como o modo de pensar aprovado, o desejo de imortalidade e a teoria dos objetos transicionais. Essas perspectivas, segundo o autor, colocam os padrões habituais sob uma nova luz e torna-se possível compreender melhor o porquê de as pessoas e as organizações geralmente acharem tão difícil conviver com a mudança.

Modo de pensar aprovado. A era das mudanças revela muitas surpresas. Nessa realidade, marcada por constantes mutações, tornam-se comuns casos de empresas que, embora tenham vivenciado períodos de sucesso, hoje lutam pela sobrevivência. Aprisionado em visões aprovadas do agir e do pensar e confiante no sucesso eterno, o gestor cria armadilhas que o impedem de pensar de maneiras inovadoras e de se transformar para atender aos constantes desafios ambientais. Seu próprio estilo particular de excelência que, na sua visão, permite enfrentar seus mundos ordenadamente, torna-se uma limitação que o impede de pensar de outra maneira, uma prisão capaz de confiná-lo dentro de realidades socialmente construídas, impedindo o surgimento de outras (Morgan, 2007).

Thiry-Cherques (1995) afirma que o comportamento resistente pode estar relacionado à dificuldade de contradizer tudo o que antes parecia tão lógico e lidar com as inevitáveis incertezas da realidade. O modo de pensar que sustentou o sucesso empresarial durante muito tempo torna-se tão lógico para o dirigente que ele não ousa reprová-lo. Para ele, é mais fácil eliminar a incerteza e proteger-se contra ela do que buscar outras maneiras de pensar que permitam lidar com elas.

Segundo Enriquez (2000a), prendendo-se a determinado modo de pensar, o indivíduo se torna fanático, o que o impede de criar alguma ideia nova e faz ele se contentar somente em defender a causa. Ou seja, não pensa na possibilidade de insucesso, não possui a consciência que os modos de ver podem se tornar modos de não ver, acrescenta Morgan (2007).

A esse respeito, Thiry-Cherques (1995) relata que as organizações têm encontrado conforto na ignorância e repousam em uma sábia ingenuidade, recusando a realidade como ela verdadeiramente se apresenta. $\mathrm{O}$ fato de as empresas estarem sendo compelidas a se transformarem e se adaptarem ou sujeitas ao próprio desaparecimento é facilmente reconhecido no mundo organizacional. Porém, embora não seja mais um sentimento recente e típico apenas desse momento da história organizacional, o autor argumenta que a resistência em aceitar o fato de que o que acontece hoje nas organizações é uma fiel imagem da seleção natural ainda persiste. Os dirigentes e as organizações se deixam levar por suposições básicas do pensamento e ignoram qualquer ideia crítica sobre suas maneiras de agir e das premissas fundamentais sobre as quais visualizam a realidade diária. Ou seja, é como se fosse uma cegueira que persiste na direção de todos os tipos de tomadas de decisão ou, como afirmam Pagès et al. (1987), uma dissolução da instância crítica.

Essa sábia ingenuidade reside na visão de que a sobrevivência é mais acidental do que é suposta e de que as forças que agem sobre as empresas funcionam mais como uma loteria do que como uma extinção dos menos aptos e menos adaptáveis (Thiry-Cherques, 1995). Nesse tipo de pensamento, mesmo sabendo que uma possível ruptura poderá vir de fora da empresa, os modos aprovados de pensar podem ser tão estruturados que mesmo a consciência da ruptura é transformada em uma visão consistente com a realidade e o modo de agir que impera na organização.

É por esse motivo que Morgan (2007) enfatiza que, embora possa parecer dramático, é possível descrever esse fenômeno como reflexo de um tipo de prisão psíquica. Como no caso da alegoria da caverna de Platão, a forma como os prisioneiros interpretavam, enxergavam e agiam em relação à realidade era tudo o que existia na concepção deles. Mesmo quando sobreveio a eles a ruptura externa, com a informação de que o modo como 
construíam a realidade da caverna consistia somente em uma imitação da verdade, não ousaram questionar seus modos de pensar e simplesmente aboliram o conselho e continuaram agindo da forma rotineira.

Desejo de imortalidade. Para Thiry-Cherques (1995), entre os fatores que explicam, de alguma forma, o comportamento resistente das pessoas frente à mudança é o tema da morte, considerado um dos fatores lógicos mais difíceis e controversos. Para Pagès et al. (1987), a angústia da morte não é um primeiro dado da psique, como defende Freud, mas é algo que se introduz nos conflitos existenciais mais profundos, que se repete, se dinamiza e se reproduz a todo o instante. Somente os indivíduos não reflexivos são capazes de negar a inquietante noção de que a vida é algo acidental e que caminha em direção a um fim (Fligstein \& McAdam, 2012). Desse modo, ao pensar sobre o tema, é possível entender que muitos atos humanos nas organizações resultam do desejo de fuga da própria mortalidade.

A esse respeito, Becker (1973) confirma que os sujeitos passam grande parte de suas vidas tentando negar todas as suas insuficiências, vulnerabilidades e a realidade da aproximação da morte. Agindo assim, eles empurram para o fundo do inconsciente seus medos mórbidos, como o medo de aniquilação e do desaparecimento, e omitem a mortalidade de qualquer tipo de discurso cotidiano.

Desse modo, é possível compreender o caráter resistente do gestor em relação às mudanças. Para ThiryCherques (1995), esse tabu da aniquilação é transferido para as organizações pelo próprio desejo de pertencimento do indivíduo e da segurança de fazer parte de uma formação social. A crise de identidade que permeia o modo de viver do gestor fez com que ele buscasse se identificar com algo que fosse capaz de lhe fornecer uma entidade abstrata e não somente a racionalidade administrativa.

Para Pagès et al. (1987), a poderosa atração do indivíduo pela organização acontece devido ao fato de ela se apresentar, pela sua própria constituição, como eterna. Freitas (2000) argumenta que, diferente das pessoas, que quando envelhecem ficam próximas da morte e distantes da sabedoria, as empresas parecem descobrir o segredo da imortalidade. Para as organizações, idade é sinônimo de sucesso e potência, ou seja, é um mergulho mais profundo na juventude. Nas entrelinhas, a empresa deixa transparecer ao indivíduo que somente a união entre eles representa a eternidade de ambos. Assim, segundo Pagès et al. (1987), a organização se constitui como um imenso sistema de defesa socialmente organizado.

Morgan (2007) declara que a forte identificação que une os indivíduos com a organização é resultante do sentimento de sentido e permanência que esta fornece ao sujeito. $O$ autor complementa que ao criar uma organização, o indivíduo busca construir estruturas de atividades maiores do que sua própria vida e que geralmente sobrevivem por muitas gerações. Ou seja, consciente de sua propensão à aniquilação, o sujeito busca se incluir em algo maior e mais duradouro do que ele mesmo.

De qualquer forma, pode-se dizer que, no íntimo, os dirigentes e os empregados captam a mensagem que a organização fornece e comportam-se como se ela fosse realmente eterna, já que o que está em jogo é muito mais do que sua simples sobrevivência, confirma Thiry-Cherques (1995). Assim, na tentativa de gerenciar e organizar o mundo empresarial, os dirigentes estão, na realidade, tentando gerenciar e organizar a si mesmos (Morgan, 2007).

Desse modo, é possível inferir que, pelo próprio sentido que fornece, qualquer ameaça contra a organização, seja compelindo-a a mudar sua estrutura, seja qualquer fator que abale a tradição de seus gestores, determina perturbações na própria capacidade cognitiva do indivíduo, segundo Thiry-Cherques (1995). Por esse motivo, internalizados sob uma ansiedade vivencial que os perseguem, os gestores desenvolvem mecanismos de defesa e buscam proteção em relação aos desconfortáveis aspectos do mundo real e às ansiedades associadas ao novo status que as mudanças exigem. Pagès et al. (1987) complementam que a ameaça da morte e sua recusa reforçam esses mecanismos de defesa psicológica.

Enriquez (2000b) retrata essa questão referindo-se aos dirigentes tecnocratas, que colocam em prática toda a sua pulsão de morte, toda a ansiedade que os envolvem, contra tudo aquilo que tenta rivalizar com seu saber e sua razão. De alguma forma, o indivíduo tenta eliminar sua própria imagem de ego fraco, buscando vencer a si mesmo e pôr-se à prova continuamente (Pagès et al., 1987).

Segundo Enriquez (2000b), a ação de qualquer mudança ameaça a integridade do gestor. Consciente de sua propensão à aniquilação e conhecedor de sua própria fraqueza, a mudança o remete a fortes angústias de destruição e ele passa a sentir o medo da quebra, do despedaçamento. É por isso que ele assume o caráter resistente e direciona fortes impulsos agressivos contra essa força ameaçadora. 
Em consequência, Morgan (2007) também considerou o fenômeno do desejo da imortalidade como uma prisão psíquica. Enriquez (2000b) afirma que o medo da morte, o medo da quebra, o medo do despedaçamento e a própria percepção e negação da realidade irrigam toda a organização. Dominados por suas angústias em relação ao seu caminho à aniquilação, os gestores constroem para si bloqueios que inibem qualquer tipo de mudança e de aprendizado.

Objetos transicionais. Há outro fenômeno que também pode ser utilizado na construção da explicação da dificuldade do gestor em aceitar as mudanças. Segundo Morgan (2007), durante toda a sua vida, o indivíduo se relaciona com objetos transicionais. Eles simbolizam o próprio sujeito e fazem a intermediação entre ele e o mundo com o qual se relaciona, ou seja, é por meio dessa relação que constrói sua própria identidade.

Fazendo uma ressalva sobre a questão da identidade, Murtagh, Gatersleben e Uzzell (2012) afirmam que a aplicação de uma perspectiva teórica sobre identidade tem o potencial de estabelecer uma ligação unidimensional entre a ameaça e a resistência. Isso porque essas teorias podem oferecer explicações sobre os processos psicológicos que delineiam as respostas do sujeito perante a identificação de uma ameaça externa. Assim, é válido considerá-las como alternativas à análise do por que os gestores acham tão difícil mudar.

Nessa teoria psicanalítica, qualquer fenômeno, conceito, ideia ou visão que, de alguma forma, assume um status de fetiche e de fixação no modo de ser do indivíduo e o impede de se libertar, é considerado um objeto transicional, ou seja, tem um significado transicional para ele. É importante ressaltar que não se trata de estereótipos. Esse fenômeno a ser preservado constitui-se em um investimento inconsciente maciço que tem o poder de invadir e transformar a vida do sujeito, pessoal e profissionalmente (Pagès et al., 1987). Assim, qualquer ação em favor da modificação desse objeto é vista pelo indivíduo como uma ameaça de sua própria existência e senso de identidade (Morgan, 2007; Murtagh et al., 2012).

Por ser um fenômeno que acompanha o indivíduo desde o seu nascimento, por meio dele é possível explicar muitos casos de resistência nas organizações. Muitas vezes, o gestor se apega a uma tradição e faz dela sua própria identidade. Dessa forma, ligado rigidamente a tal fenômeno, ele se torna incapaz de progredir em meio a tantas mutações que ocorrem ao seu redor, visto que suas próprias atitudes se tornam congeladas e o impedem de pensar de qualquer outra forma. É por esse motivo que Morgan (2007) afirma que, nesses casos de apego a um fenômeno qualquer, o próprio desenvolvimento humano fica bloqueado e distorcido.

O apego a determinado fenômeno torna-se algo tão concreto para o gestor que ele constrói sua realidade organizacional baseando-se nessa identificação. Assim, diante de qualquer pressão para a mudança, sua própria dinâmica inconsciente faz ele ter reações muitas vezes desproporcionais à própria importância do assunto. Pagès et al. (1987) complementam que essas pressões são penetrações em abismos insondáveis, ou seja, não se constituem somente como ameaças externas, mas são substituídas e ampliadas pela própria angústia psicológica que geram.

\section{DISCUSSÃO}

Este artigo buscou construir uma reflexão diferenciada sobre o tema da resistência à mudança. Respaldado pela psicanálise, objetivou analisar como forças inconscientes podem fazer os gestores adotarem comportamentos resistentes à mudança organizacional, mesmo ela sendo imprescindível para a sobrevivência. Para tal, realizou-se um estudo bibliográfico de caráter exploratório e explicativo, visando construir uma reflexão desafiadora da visão paradigmática que envolve este tema.

Com a realização do estudo é possível afirmar que as análises predominantes acerca do comportamento resistente dos indivíduos são feitas de forma superficial. Pouca atenção é dada à personalidade dos indivíduos e aos seus processos inconscientes. São vistos somente como sujeitos lógicos e racionais que naturalmente resistem aos processos que os desestabilizem. Tal superficialidade parece nos levar à utopia de que é possível simplificar algo tão complexo, não considerando a multiplicidade psíquica interiorizada em cada indivíduo.

Portanto, conclui-se que é pela análise profunda da subjetividade do sujeito e dos processos inconscientes que se compreende o comportamento resistente, em especial o do gestor. O estudo mostrou que grande parte desse comportamento reflete das lutas internas que ocorrem nesses indivíduos. Reconhecendo-o como ser que pensa, sente, interpreta e constrói significados é suficiente para inferir que seus traços comportamentais não resultam apenas de processos exteriores, mas são reflexos da própria incapacidade de resolução de suas tensões. Isso porque, fundamentando-se nos ideais de Jung (1953, como citado em Morgan, 2007, p. 240), o gestor 
é internalizado por uma sombra reprimida, um depósito de angústias e ansiedades que o impede de aceitar qualquer modificação em seu espaço.

Remetendo-nos às abordagens psicanalíticas da metáfora analisada, essas angústias reprimidas vão desde a incapacidade do gestor em lidar com novas maneiras de pensar até o medo da aniquilação e da perda da identidade que carrega consigo. Confinado em modos de pensar e apegado em conceitos estabelecidos, torna-se incapaz de aceitar aquilo que é incerto ou que, de certa forma, simbolize uma ruptura em seus modos de encarar a realidade e o deixa vulnerável à sua mortalidade.

É devido a essas questões que se torna impossível analisar o tema da resistência à mudança sem considerar também as dimensões inconscientes e subjetivas. Sem dúvida, é o próprio processo cognitivo do indivíduo que influencia a adoção desse comportamento e buscar entendê-lo interiormente e psiquicamente é um caminho crítico para a compreensão do tema. O gestor sofre o domínio de outro interior, cujas forças ocultas o induzem a resistir a qualquer mudança que altere sua maneira habitual de encarar a realidade que o cerca.

É por este motivo que Pagès et al. (1987) afirmam que a mudança não pode ser esperada unicamente de medidas econômicas e políticas, mas também da reestruturação das defesas inconscientes do gestor.

Em suma, pode-se dizer que para compreender a resistência à mudança, recorrer ao universo psicanalítico possibilita entender um fenômeno tão complexo. Portanto, este estudo pode servir de inspiração para novas pesquisas, como, por exemplo, buscar compreender as diferenças que possivelmente existem no comportamento do gestor profissional e do gestor proprietário, quando submetidos à mudança. Além disso, este artigo limitou-se à figura do gestor. Mas, voltando-se aos funcionários de uma organização e mantendo a mesma abordagem do estudo, a conclusão seria a mesma tratando-se de sua resistência?

\section{REFERÊNCIAS}

Becker, E. (1973). The denial of death. New York: Free Press.

Bringselius, L. D. (2010). Resistance to change: Four interpretations. Lund Institute of Economic Research, Working Paper Series, 1. Recuperado de http://bit.ly/16yPAzs.

Dias, R. (2008). Sociologia das organizações. São Paulo: Atlas.

Dimaggio, P. (1997). Culture and cognition. Annual Review of Sociology, 23, 263-287. doi: 10.1146/annurev.soc.23.1.263.

Enriquez, E. (2000a). O indivíduo preso na armadilha da estrutura estratégica. In F. C. P. Motta, \& M. E. de Freitas (Eds.), Vida psíquica e organização (pp.23-40). Rio de Janeiro: Editora FGV.

Enriquez, E. (2000b). Vida psíquica e organização. In F. C P., Motta, \& M. E. de Freitas (Eds.), Vida psíquica e organização (pp.11-22). Rio de Janeiro: Editora FGV.

Fischer, G. N. (2010). Espaço, identidade e organização. In J. F. Chanlat (Ed.), O indivíduo e a Organização: Dimensões esquecidas (Vol. 2, pp.81-102). São Paulo: Atlas.

Fleck, D. (2007). Institutionalization and organizational long-term success. BAR, Brazilian Administration Review, 4(2), 64-80. doi: http://dx.doi.org/10.1590/S1807-76922007000200005

Fligstein, N., \& McAdam, D. (2012). A theory of fields. New York: Oxford.

Freitas, M. E. de. (1999). Cultura Organizacional: Identidade, sedução e carisma? Rio de Janeiro: Editora FGV.

Freitas, M. E. de. (2000). A questão do imaginário e a fronteira entre a cultura organizacional e a psicanálise. In F. C. P. Motta, \& M. E. de Freitas (Eds.), Vida psíquica e organização (pp. 41-73). Rio de Janeiro: Editora FGV.

Gaarder, J. (1995). O mundo de Sofia: Romance da história da filosofia. (J. Azenha Jr., Trad.). São Paulo: Companhia das Letras. (Obra original publicada em 1991).

Grün, R. (1999). Modelos de empresas, modelos de mundo: Sobre algumas características da nova ordem econômica e da resistência à ela. Revista Brasileira de Ciências Sociais, 14(41), 121-140. doi: http://dx.doi.org/10.1590/S010269091999000300008

Hernandez, J. M., \& Caldas, M. P. (2001). Resistência à mudança: Uma revisão crítica. Revista de Administração de Empresas, 41(2), 31-45. doi: http://dx.doi.org/10.1590/S0034-75902001000200004

Lapierre, L. (2010). Interioridade, gestão e organização da realidade psíquica como fundamento da gestão. In J. F. Chanlat (Ed.), O indivíduo e a organização: Dimensões esquecidas (Vol. 2, pp.253-268). São Paulo: Atlas.

Lewin, K. (1947). Frontiers in group dynamics. Human Relations, 1(1), 5-41. doi: 10.1177/001872674700100201. 
Moreira, C. A. A. (2005). O paternalismo nas organizações brasileiras: Reflexões à luz da análise cultural de empresas do Pólo Têxtil de Americana (Tese de doutorado). Recuperado de http://bibliotecadigital.fgv.br/dspace/handle/10438/2465?show=full

Morgan, G. (2007). Imagens da organização (2a ed.). (G. G. Goldschmidt, Trad.). São Paulo: Atlas. (Obra original publicada em 1998).

Motta, P. R. (1998). Transformação organizacional: A Teoria e a Prática de Inovar. Rio de Janeiro: Qualitymark Ed.

Murtagh, N., Gatersleben, B., \& Uzzell, D. (2012). Self-identity threat and resistance to change: Evidence from regular travel behavior. Journal of Environmental Psychology, 32(4), 318-326. doi:10.1016/j.jenvp.2012.05.008

Neri, Aguinaldo (Org.). (2005). Gestão de RH por competências e a empregabilidade (2a ed.). Campinas: Papirus.

Pagès, M., Gaulejac, V. de., Bonetti, M., \& Descendre, D. (1987). O poder das organizações (M. C. Tavares, \& S. S. Favatti, Trads.). São Paulo: Atlas. (Obra original publicada em 1979).

Robbins, S. P., Judge, T. A., \& Sobral, F. (2010). Comportamento organizacional (14a ed.). (R. de C. Gomes, Trad.) São Paulo: Pearson Prentice Hall. (Obra original publicada em 1943).

Silva, J. R., \& Vergara, S. C. (2003). Sentimentos, subjetividade e supostas resistências à mudança organizacional. Revista de Administração de Empresas, 43(3), 10-21. doi: http://dx.doi.org/10.1590/S0034-75902003000300002

Souza, V. L. de. (2002). Gestão de desempenho: Julgamento ou diálogo. Rio de Janeiro: Editora FGV.

Spector, P. E. (2002). Psicologia das organizações. São Paulo: Saraiva.

Thiry-Cherques, H. R. (1995). A rebeldia conservadora - Aspectos da resistência à modernização nas organizações brasileiras. Revista de Administração de Empresas, 35(1),30-37. doi: 10.1590/S0034-75901995000100005

Thomas, R., \& Hardy, C. (2011). Reframing resistance to organizational change. Scandinavian Journal of Management, 27(3), 322-331. doi:10.1016/j.scaman.2011.05.004

Vergara, S. C. (2009). Projetos e relatórios de pesquisa em administração (11a ed. rev.). São Paulo: Atlas.

Zucker, L. G. (1977). The role of institutionalization in cultural persistence. American Sociological Review, 42(5), 726-743. Recuperado de http://bit.ly/15974Lw 